\title{
Multiple cotton wool spots following bone marrow transplantation for treatment of acute lymphatic leukaemia*
}

\author{
B GLOOR, A GRATWOHL, H HAHN, S KRETZSCHMAR, Y ROBERT, \\ B SPECK, AND B DAICKER
}

From the Department of Ophthalmology and the Department of Haematology, University of Basle, Switzerland

SUMmaRY Three patients with acute lymphatic leukaemia developed visual impairment due to occlusion of small retinal vessels with multiple cotton wool spots after treatment which included whole body and skull irradiation followed by bone marrow transplantation and cyclosporin A. Withdrawal of cyclosporin A and treatment with corticosteroids was followed by recovery of visual acuity. This retinopathy and the retinal changes seen in the immunodeficiency syndrome are thought to be closely related. The possible role of cyclosporin A is discussed, though cotton wool spots and retinal haemorrhages have never been described in renal transplant patients during treatment with this drug. Withdrawal of cyclosporin $\mathrm{A}$, which is highly effective in preventing graftversus-host disease, can be fatal. Irradiation of the skull prior to bone marrow transplantation and intrathecal administration of methotrexate may be the most important factors causing the retinal ischaemic signs described here. The inclusion of an ophthalmologist in the team monitoring transplant patients would lead to increased documentation and a better understanding of this disease.

We have recently seen three patients who developed severe visual loss two to three months after bone marrow transplantation. The ophthalmoscopic substrate of this visual loss was a disseminated multifocal ischaemic retinopathy with extensive cotton wool patches and retinal haemorrhages. All three patients had received irradiation to the head in addition to whole body irradiation and had been treated with cyclosporin A to prevent graft-versus-host disease.

The heavy maintenance immunosuppression which patients with bone marrow grafts receive suggests a possible connection between this retinopathy and that observed in the 'immunodeficiency syndrome.' However, to the best of our knowledge multifocal ischaemia of the retina with multiple cotton wool spots has not yet been reported as a complication of bone marrow transplantation.

The question therefore arises whether cyclosporin

${ }^{*}$ Read in part at the Washington University Eye Alumni Meeting, St Louis, Missouri, 29 April 1983.

Correspondence to Professor B. Gloor, Universitäts-Augenklinik, Mittlere Strasse 91, 4056 Basel, Switzerland.
A was directly or indirectly involved in the disease process. These three cases described here may also help us to understand what is going on in the retina in the immunodeficiency syndrome.

\section{Case reports}

CASE 1

A female, born on 29 March 1961.

Primary disease. Acute lymphatic leukaemia, Calla positive, diagnosed in October 1981. Induction therapy: vincristine, prednisone, daunorubicin, Lasparaginase. Complete remission in November 1981. In November and December irradiation of the skull with 2400 rads, combined with methotrexate, mercaptopurine, vincristine, and prednisone.

Bone marrow transplantation was performed on 9 March 1982 after treatment with cyclophosphamide $60 \mathrm{mg} / \mathrm{kg}$ body weight, two doses, and following irradiation of the whole body with 1000 rads. To prevent graft-versus-host disease cyclosporin A was given at a dose of $20 \mathrm{mg} / \mathrm{kg}$ body weight the day 
before, $10 \mathrm{mg} / \mathrm{kg}$ on the day of transplantation, then 5 $\mathrm{mg} / \mathrm{kg}$ for 11 days, $600 \mathrm{mg}$ by mouth for four weeks, later reduced to $450 \mathrm{mg}$ per day. The dose of cyclosporin A was reduced when the serum creatinine increased slightly and oedema of the face developed.

Eye disease. A complete eye examination performed on 26 February 1982 prior to bone marrow transplantation was normal. Three months after bone marrow transplantation the patient noted hazy vision in the right eye. A subsequent eye examination on 6 September 1982, three months after bone marrow transplantation, showed the following: Visual acuity RE $0.7-0.8$ partially unaided, LE 0.8-1.0 partially unaided. With the Amsler grid a paracentral scotoma below was shown on the right side; the left eye was normal. Pupil reactions were normal. Round the disc and the macula multiple typical cotton wool spots and some haemorrhages in the nerve fibre layer were found. No sheathing of vessels and no cells in the vitreous could be found.

The patient's general health at this time was good. Blood pressure measurements were always normal apart from a single reading of $160 / 90 \mathrm{mmHg}$ in February 1982 . Hb $10 \cdot 1 \mathrm{~g} / \mathrm{dl}$, leucocytes $2.6 \times 10^{9} / 1$, normal differential count, thrombocytes $168 \times 10^{9} / 1$. There was no evidence of platelet dysfunction at this stage. Two and a half weeks later her visual acuity decreased over the course of a few days and on 29 June was RE 0.05, LE 0.2-0.3. Amsler grid: patchy central scotoma on the right and a large scotoma below fixation on the left. Fundus examination showed a great increase in the number of cotton wool spots, which were becoming confluent (Figs. 1a, b), and more intraretinal haemorrhages were evident. The arterioles were narrow, the veins dilated. Goldmann fields showed: paracentral scotoma in both eyes for $I_{2}, I_{3}$, and $I_{4}$. Therapy with cyclosporin A was stopped, and prednisone $100 \mathrm{mg} /$ day was given for 14 days, then in lower doses. In the following weeks the cotton wool patches regressed slowly and the scotomas in the Amsler grid disappeared, though fine retinal folds and some hard exudates were still visible at the right posterior pole. Six weeks after the patient started treatment with steroids her visual acuity RE was $0 \cdot 7$, LE 0.9 (Figs. 2a, b).

Follow-up. The patient remained well until the end of January 1983, when paraesthesiae developed in the left arm. On 3 February the patient was admitted to hospital after the onset of a left temporal sensory hemisyndrome 1 to 2 days previously. Neither a CT scan nor an electroencephalogram (EEG) showed any definite abnormality. A sensory Jacksonian-type epilepsy was suspected. Vascular disease, such as a cortical vein thrombosis, and leukaemic infiltration were considered as possible causes.

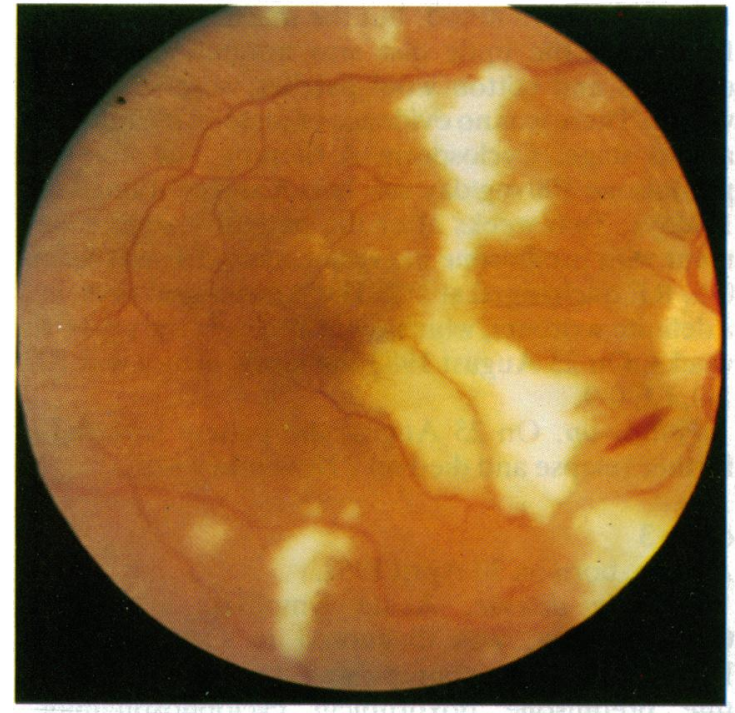

Fig. 1a

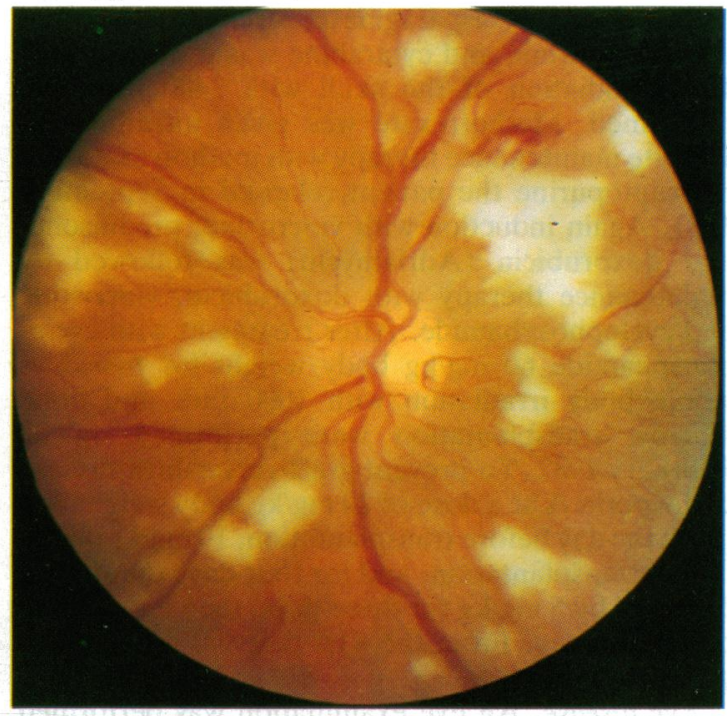

Fig. 1b

Fig. 1 Case 1: Fundus pictures taken on 29 June 1982. (a) Right eye. Confluent cotton wool spots, white ischaemic oedema reaching to the foveola (VA 3/60!). Note that centrally the vessels are nowhere obscured by the white material. Flame shaped haemorrhages unrelated to the white areas. Small vessels crossing the disc margin at 8 o'clock. (b) Left eye shows similar changes, but disc margin more blurred than in the right eye. Macula less affected (VA 6/24). 


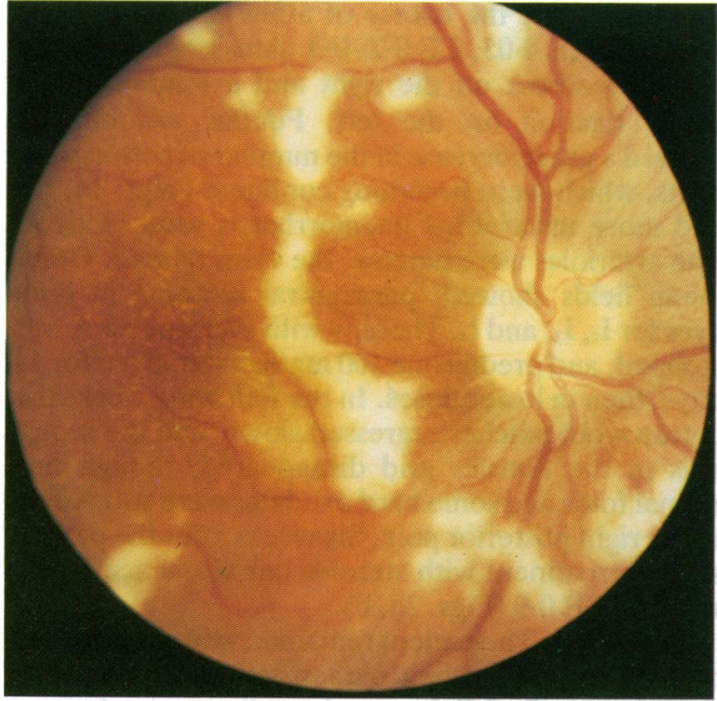

Fig. 2a

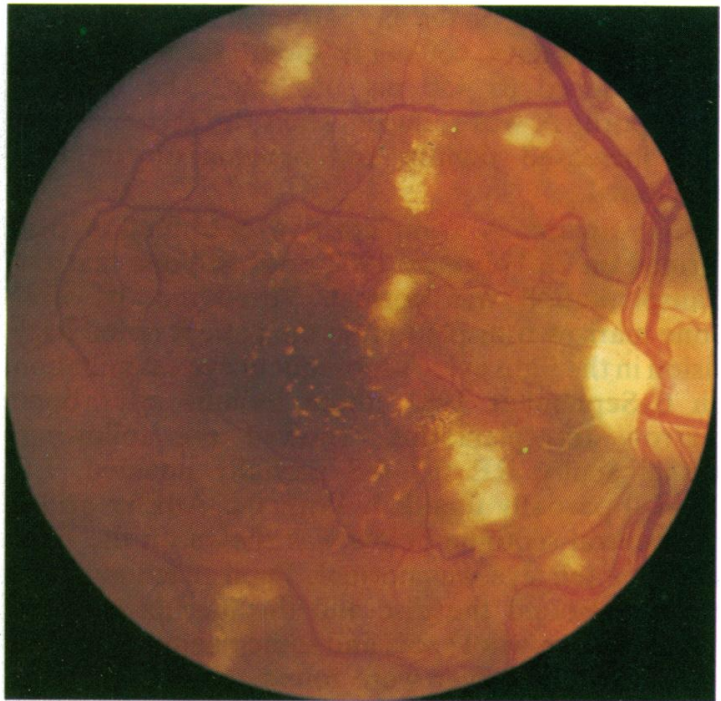

Fig. 2b

Fig. 2 Case 1: Follow-up of right eye. (a) 14 July: parafoveal cotton wool spots regressing; hard exudates in the macular region. (b) 30 August: cotton wool spots are disappearing; hard exudates more pronounced.

\section{CASE 2}

A male born on 11 March 1962.

Primary disease. Acute lymphatic leukaemia, Calla positive, was diagnosed in April 1981. Riehm's induction therapy with vincristine, prednisone, daunorubicin, L-asparaginase, cyclophosphamide, mercaptopurine, and cytarabine was given. In May 1981 irradiation of the skull with 2400 rads was performed. Methotrexate was given intrathecally. Despite maintenance therapy with methotrexate and mercaptopurine the patient relapsed in September 1981. Again induction with vincristine, prednisone, and doxorubicin (Adriamycin) was followed by maintenance therapy with doxorubicin, vincristine and cyclophosphamide. After treatment with cyclophosphamide $60 \mathrm{mg} / \mathrm{kg}$ body weight for two days whole body irradiation with 1000 rads and bone marrow transplantation were performed on 27 February 1982. To prevent graft-versus-host disease cyclosporin A at a dose of $20 \mathrm{mg} / \mathrm{kg}$ body weight was given the day before transplantation, $10 \mathrm{mg} / \mathrm{kg}$ on the day of transplantation, and for four days thereafter, followed by $5 \mathrm{mg} / \mathrm{kg}$ for three days, then a reduction to $200 \mathrm{mg} /$ day. From the $41 \mathrm{st}$ day $800 \mathrm{mg} /$ day was given orally.

Eye disease. An eye examination was performed on 15 April 1982 prior to bone marrow transplantation. Visual acuity was RE $1 \cdot 0-1 \cdot 2$, LE $1 \cdot 0-1 \cdot 2$; fundus RE normal, LE small round haemorrhages in the region of the inferotemporal vascular arcade. Eight days after bone marrow transplantation the patient noted a brief disturbance of accommodation. Because he complained of visual loss, another eye examination was performed on 5 August 1982. Visual acuity was then RE $1 \cdot 0$, LE $0 \cdot 1$. In the RE fine haemorrhages at the margin of the disc and cotton wool spots were noted, but the macula was normal. In the LE the optic disc was normal, but haemorrhages and cotton wool patches were seen elsewhere. There was no evidence of platelet dysfunction at this stage. Cyclosporin A therapy was stopped, prednisone $100 \mathrm{mg} /$ day was begun and continued for 14 days. Two weeks after the patient started treatment with prednisone his visual acuity LE was again $0 \cdot 5, \mathrm{RE}$ unchanged at $1 \cdot 2$. The Amsler grid revealed a definite scotoma, which regressed over the next two weeks. On 23 August 1982 the visual acuity was RE $1 \cdot 0$, LE $0 \cdot 9$.

Follow-up. On 25 August the patient suffered a further relapse and died on 2 November 1982.

\section{CASE 3}

A male, born on 30 April 1962.

Primary disease. Acute lymphatic leukaemia, Calla positive, was diagnosed in October 1981. Riehm's induction therapy was started with vincristine, prednisone, doxorubicin, cyclophosphamide, L-asparaginase, methotrexate, and cytarabine. In December 1981 irradiation of the skull was performed with 2000 rads and methotrexate was given intrathecally four times. After treatment with cyclophosphamide $60 \mathrm{mg} / \mathrm{kg}$ twice, whole body irradiation 
with 1000 rads and bone marrow transplantation were performed on 17 September 1981. To prevent graft-versus-host disease cyclosporin A was given 20 $\mathrm{mg} / \mathrm{kg}$ body weight the day before transplantation, then $10 \mathrm{mg} / \mathrm{kg}$ for four days starting on the day of transplantation, then $5 \mathrm{mg} / \mathrm{kg}$ for 14 days, $700 \mathrm{mg} /$ day orally.

Eye disease. An eye examination 11 days before bone marrow transplantation showed normal findings. The visual acuity was RE $1.0, \mathrm{LE} 1.0$ unaided. On 9 December the patient noted visual disturbance and examination revealed a visual acuity of RE $0 \cdot 4$, LE 0.1. Large cotton wool spots and haemorrhages were seen in the fundus of both eyes. One day later both eyes showed multiple cotton wool spots, small haemorrhages, and a Cellophane maculopathy, while in the LE the retina above the papillomacular bundle was oedematous and swollen, giving the appearance of a branch arterial occlusion. In the macula a small serous detachment had appeared.

Visual field examination on 13 January showed a field defect corresponding to this lesion. There was no evidence of platelet dysfunction at this stage.

Follow-up. Cyclosporin A was stopped and prednisone $100 \mathrm{mg} /$ day was given. After 14 days the dosage was reduced. The visual acuity was RE 0.8, LE 0.8. Clinically the patient was well and the bone marrow showed a full remission. Later he developed bronchopneumonia and fibrosing alveolitis (proliferative stage) and died on 10 February 1983 . The necropsy showed no signs of a relapse of the acute leukaemia and no obstructive disease of the vessels in the kidney.

Eye at necropsy. A few fine cotton wool spots were visible in the parapapillary region of the right globe. Histology revealed the presence of cytoid bodies in both eyes (Fig. 3), thus confirming unequivocally the clinical diagnosis of cotton wool spots. Step-serial sections did not show any abnormality of the blood vessels supplying the areas of retina containing cotton wool spots, nor was there any evidence of retinal inflammation or infection.

\section{Discussion}

The cotton wool spots seen in our patients may be regarded as an expression of small vessel disease, the site of obstruction being at small arterioles, precapillaries, and/or in the capillary bed.

This clinical picture of bilateral cotton wool spots and retinal haemorrhages must be distinguished from the fundus appearance of partial central retinal artery occlusion. ${ }^{1}$ The latter condition, which affected only one eye in each of the seven patients described, ${ }^{1}$ is characterised by multiple peripapillary cotton wool spots and mild ischaemic swelling of the inner retina but almost complete absence of retinal haemorrhages. Furthermore all patients were suffering from either temporal arteritis, severe hypertension, or embolism.

The multifocal ischaemia of the retina which we describe here could have been caused by any one of a

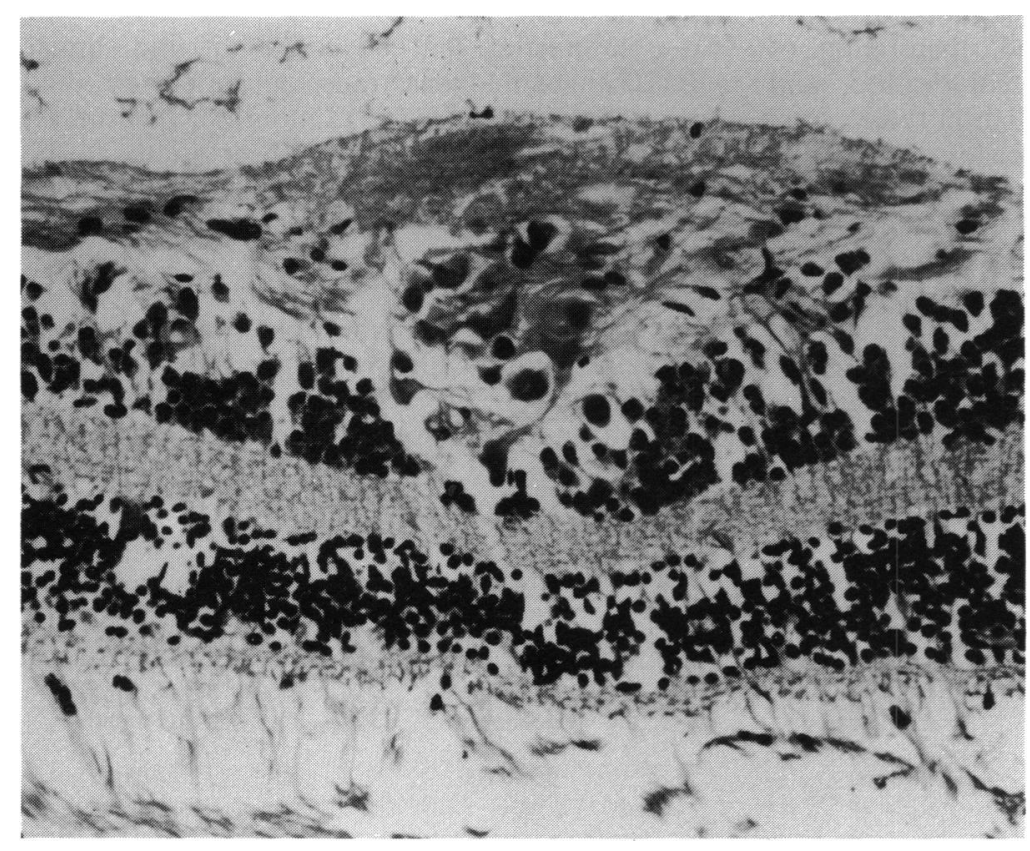

Fig. 3 Case 3: Typical histological appearance of a cotton wool spot: swelling of the nerve fibre layer and formation of cytoid bodies. (Haematoxylin and eosin, $\times 220$ ). 
large number of conditions, including iatrogenic factors, infections, immunological or haematological disorders, or vascular disease. However, the most probable causes are acquired immunodeficiency, radiation combined with intrathecal methotrexate, or the administration of cyclosporin A. Viral infections such as cytomegalovirus or herpes simplex, graft-versus-host disease, anaemia, hypertension, and platelet deposition represent less likely causes.

If disseminated retinal ischaemia severe enough to produce visual loss, as in our patients, was caused solely by the immunosuppressives commonly employed in bone marrow transplantation, one would have expected other investigators to have reported this complication, since around 1000 marrow transplants have now been performed. Clearly we must seek other causes, such as radiation and/or cyclosporin $A$. It is possible that irradiation of the skull with subsequent irradiation of the whole body and the intrathecal administration of methotrexate may predispose to retinal vascular damage. The eye disease would then have its counterpart in the brain: that is, multifocal leucoencephalopathy, which, in contrast to the eye disease, is a known complication in patients given the pretransplantation treatment employed here. The sensory Jacksoniantype epilepsy in our first patient provides some support for this view, although the ocular vessels at this stage no longer showed any evidence of vascular obstruction either in the arterioles, capillaries, or veins. Nevertheless, in none of our three patients does the retinal disease resemble the classical picture of radiation retinopathy, which in addition to cotton wool spots shows sheathing and obliteration of vessels, microaneurysms, neovascularisation, and hard exudates. ${ }^{2}$ Furthermore, radiation retinopathy is usually progressive and does not respond to therapy.

The question whether cyclosporin A was directly or indirectly responsible for the retinal changes seen in our three patients must be seriously considered for two reasons. Firstly, although visual symptoms did not occur until some 6-16 months after the diagnosis of leukaemia and irradiation of the skull, the interval between whole body irradiation, bone marrow transplantation, and administration of cyclosporin A and the onset of visual symptoms was only $2-31 / 2$ months
(Table 1.) Secondly, the most important action of cyclosporin $\mathrm{A}$ is suppression of T-helper lymphocytes, ${ }^{34}$ thus producing a situation very similar to that seen in patients with the immunodeficiency syndrome,${ }^{56}$ so long as the picture is not complicated by retinal infection, usually due to cytomegalovirus or Pneumocystis carinii. Pepose et al. ${ }^{7}$ stressed that microvascular and infectious diseases of the retina must not be confused with each other. This is clinically important, because retinal changes due to microvascular disease may respond to steroid therapy, whereas if an infection is also present steroids may lead to disaster, at least if given on their own. In one of our three cases we could demonstrate the presence of typical cotton wool spots histologically, with no evidence of an infectious disease.

But patients with collagen diseases such as lupus erythematosus, dermatomyositis, and scleroderma may also present a similar clinical picture. In dermatomyositis the number of cotton wool spots often exceeds what would be expected from the level of arterial hypertension seen in these patients. All these conditions are autoimmune diseases in which antinuclear antibodies are found and in which the $T$ helper cells may be suppressed as by cyclosporin A.

Cyclosporin A does not suppress secondary responses. It has no cytotoxic effect and does not lower resistance to bacterial or fungal infections. ${ }^{34}$ It is most effective in the treatment of graft-versus-host disease, being literally life-saving for many patients, so that extreme caution is indicated before cyclosporin A is implicated as the cause of the retinopathy described here.

It is interesting that we could not find similar retinal changes in 14 renal transplant patients who had received cyclosporin A for 12 months (Oechslin A, Thiel G, Gloor B, personal observations to be published) even though one might expect such changes in patients with kidney disease. On the other hand one of the authors together with Mihatsch (Daicker B, Mihatsch MJ, unpublished observations) has recently found histologically ischaemic optic neuropathies with atrophy of the inner retinal layers in young, healthy rats treated with cyclosporin A. These findings suggest a direct effect of cyclosporin A on small vessels of the retina and/or optic nerve.

Table 1 Time intervals between ischaemic retinopathy (cotton wool spots) and various therapies

\begin{tabular}{|c|c|c|c|}
\hline & Case 1 & Case 2 & Case 3 \\
\hline $\begin{array}{l}\text { Diagnosis of leukaemia } \\
\text { Irradiation of the skull } \\
\text { Whole body irradiation, }\end{array}$ & $\begin{array}{l}9 \text { months } \\
6 \text { months }\end{array}$ & $\begin{array}{l}16 \text { months } \\
15 \text { months }\end{array}$ & $\begin{array}{l}14 \text { months } \\
12 \text { months }\end{array}$ \\
\hline $\begin{array}{l}\text { Bone marrow transplantation, } \\
\text { Therapy with cyclosporin A }\end{array}$ & 90 days & 100 days & 53 days \\
\hline
\end{tabular}


Unfortunately cyclosporin A was stopped in each of our cases as soon as retinopathy was recognised. We cannot therefore say whether these cases responded to steroids, which were started only when cyclosporin A therapy was stopped. However, it is important to note that the disease process in the retina was reversible. The lack of inflammation in the anterior segment and the complete absence of cells in the vitreous virtually exclude most viral infections. No foci of retinal necrosis, characteristic of cytomegalovirus infection, were seen, neither did the typical pale chorioretinal scars develop subsequently.

The most important ocular complication of graftversus-host disease affects the anterior segment, ${ }^{8-10}$ where a condition resembling Sjögren's disease was first described by Gratwohl et al." None of our patients complained of dry eyes. Retinal changes suggesting microvascular disease have not been described in patients with graft-versus-host disease, and the occurrence of haemorrhages in the retina and vitreous probably reflects pancytopenia. ${ }^{12} 13$

Our patients were not anaemic and suffered neither from extreme arterial hypertension nor from hypotension. In none of the three patients was there any evidence that platelet deposition was occurring elsewhere in the body during the period over which the cotton wool spots developed. Nor were any signs of a coagulopathy detected suggesting that platelet dysfunction was not responsible for the retinal changes observed.

In conclusion, the cause of the multifocal retinal ischaemic disease in our three patients remains obscure. It is clearly desirable that all patients submitted to bone marrow transplantation should be examined by an ophthalmologist whether or not they are receiving cyclosporin A. A careful study of renal transplant patients should also be undertaken in an attempt to elucidate any connection between cyclosporin A and the development of retinopathy.

The authors are grateful to G Sturrock, MD, for thorough revision of the English of this manuscript.

We thank Professor Dr Ph Heitz, chairman of the Department of Pathology, for allowing us to use the necropsy protocol of case 3 for this paper.

\section{References}

1 Oji EO, McLeod D. Partial central retinal artery occlusion. Trans Ophthalmol Soc UK 1978; 98: 156-9.

2 Brown GC, Shields JA, Sanborn G, Augsburger JJ, Savino PJ, Schatz NJ. Radiation retinopathy. Ophthalmology 1982; 89: 1494-501.

3 Borel JF. Cyclosporin-A. Pharmacology. Basle: Sandoz, 1982.

4 Morris PJ. Cyclosporin-A. Transplantation 1981; 32: 349-54.

5 Holland GN, Gottlieb MS, Yee RD, Schanker HM, Pettit TH. Ocular disorders associated with a new severe acquired cellular immunodeficiency syndrome. Am J Ophthal 1982; 93: 393-402.

6 Newmann NM, Mandel MR, Gullet J, Fijikawa L. Clinical and histological findings in opportunistic ocular infections. Arch Ophthalmol 1983; 101: 396-401.

7 Pepose JS, Nestor MS, Holland GN, Cochran AJ, Foos RY. An analysis of retinal cotton wool spots and cytomegalovirus retinitis in the acquired immunodeficiency syndrome. Am J Ophthalmol 1983; 95: 118-9.

8 Jack MK, Jack GM, Sale GE, Shulman KM, Sullivan KM. Ocular manifestations of graft-vs-host disease. Arch Ophthalmol 1983; 101: 1080-4.

9 Kincaid MC, Green WR. Ocular and orbital involvement in leukemia. Surv Ophthalmol 1983; 27: 211-32.

10 Franklin RM, Kenyon KR, Tutschka PJ, Saral R, Green WR, Santons GW. Ocular manifestations of graft-vs-host disease. Ophthalmology 1983; 90: 4-13.

11 Gratwohl AA, Moutsopoulos HM, Chused TM, et al. Sjögrentype syndrome after allogeneic bone marrow transplantation. Ann Intern Med 1977; 87: 703-6.

12 Hirst LW, Jabs DA, Tutschka PJ, Green WR, Santons GW. The eye in bone marrow transplantation. Arch Ophthalmol 1983; 101: $580-4$.

13 Jabs DA, Hirst LW, Green WR, Tutschka PJ, Santons GW, Beschorner WE. The eye in bone marrow transplantation. Arch Ophthalmol 1983; 101: 585-90. 